\title{
A REPRESENTAÇÃO DA MODERNIDADE NA POESIA DE CHARLES BAUDELAIRE
}

\author{
Edgar Roberto Kirchof ${ }^{1}$
}

Resumo: O presente artigo aborda a poesia de Charles Baudelaire, a partir da maneira como o poeta representa o tema da Modernidade, em As flores do mal. Baudelaire retrata esse tema principalmente através da imagem da cidade, bem como de objetos urbanos. $\mathrm{O}$ artigo divide-se em duas partes. Inicialmente, discute-se a maneira como a crítica literária tem compreendido a vinculação da poesia baudelairiana com o tema da Modernidade. Nessa seção, são apresentados os principais conceitos a partir dos quais é possível compreender como Baudelaire concebia as transformações sociais e históricas de sua época, especialmente o spleen, o erotismo e o satanismo. Na segunda parte, esses problemas passam a ser abordados a partir dos Quadros parisienses, em As flores do mal, analisando-se, em profundidade, o poema Paysage.

Palavras-chave: Charles Baudelaire, Flores do mal, Quadros parisienses, Modernidade, Cidade.

Abstract: The present article approaches the poetry of the French author Charles Baudelaire from the point of view of the way he represents Modernity in Les Fleurs $d u$ Mal. It is the purpose of this article to demonstrate that Baudelaire relates Modernity to images of the city. The article is structured in two parts. It begins by bringing out some of the main concepts usually ascribed to Baudelaire in the context of the literary criticism concerning his understanding of Modernity. In this section some of the main concepts related to the way Baudelaire understands the social and historical changes that are taking place in his own time are presented, especially spleen, eroticism and Satanism. In the second part these issues are approached by means of an analysis of the Tableaux Parisiens, in Les Fleurs $d u$ Mal, especially the poem Paysage.

Key words: Charles Baudelaire, Les Fleurs du Mal, Tableaux Parisiens, Modernity, City.

\section{A Cidade Como IMAgem da Modernidade}

Jürgen Habermas (1990, p. 19) defende a tese segundo a qual o modernismo estético surge já no início do século XVIII, com a discussão entre os classicistas franceses, de um lado, e os assim-chamados modernos, de outro. Estes últimos negavam o conceito aristotélico da perfeição estética - desligada do tempo e, por isso mesmo, eterna - defendida pelos primeiros. Amparados pela nova noção de progres-

1 Doutor em Teoria da Literatura pela Pontifícia Universidade Católica do Rio Grande do Sul - PUC/RS; docente da Universidade Luterana do Brasil - ULBRA, campus Canoas. Endereço eletrônico: ekirchof@hotmail.com 
so, tal qual fora sugerida pelas então incipientes Ciências da Natureza, os modernistas propunham o belo como totalmente relativo e vinculado ao tempo. O filósofo alemão afirma que é, portanto, no domínio estético que a questão da fundamentação da modernidade a partir de si própria se coloca pela primeira vez na sua história.

A maior parte dos críticos de literatura, por outro lado, afirma que a poesia moderna inicia apenas com Charles Baudelaire. Um dos estudos que certamente mais contribuiu para a solidificação dessa perspectiva - entrementes um clássico foi realizado pelo filósofo alemão Walter Benjamin (1997), que focalizou a poesia de Baudelaire a partir de sua modernidade estética. Segundo G. M. Hyde, "a literatura modernista nasceu na cidade, e com Baudelaire - principalmente com sua descoberta de que as multidões significam solidão e que os termos multitude e solitude são intercambiáveis para um poeta de imaginação fértil e ativa" (HYDE, 1989, p. 275). Michael Hamburger (HAMBURGER, 1991, p. 272) acredita que Baudelaire deva ser considerado o pai da poesia moderna, visto que o poeta concilia, pela primeira vez na história da literatura, dois pontos de vista até então antagônicos, a saber, $o$ elemento contemporâneo e o intemporal, mediante o uso alegórico das imagens urbanas (Idem, p. 15). Numa perspectiva semiótica, Walter A. Koch afirma que o modernismo de Baudelaire - assim como dos demais simbolistas - consiste na radicalização do foco estilístico da linguagem em detrimento do foco informacional (KOCH, 1993, p. 134). Como se percebe, a modernidade de Baudelaire está ligada ao fato de ser ele o primeiro poeta a eleger a cidade grande como objeto poético, concedendo, a esse tema, um tratamento estilístico inusitado.

Apesar de a demarcação temporal do Modernismo ou da Modernidade ser um assunto controvertido entre pensadores vinculados às artes, à filosofia e à história ${ }^{2}$, parece não haver contendas quando se trata de assinalar o caráter moderno da poesia baudelairiana. Em Baudelaire, de um lado, o respeito pela tradição se torna visível pelo uso rigoroso que faz da forma em sua poesia. O poeta não só respeita a versificação clássica, que prefere versos alexandrinos, como lhes investe de vários recursos técnicos e estilísticos, tais como rimas internas (Je verrai l'atelier .../Les tuyaux, les clochers...) e muitas aliterações, como Les deux mains au menton, du haut de ma mansarde, ou L'étoile dans l'azur, la lampe à la fenêtre.

De outro lado, contudo, o poeta francês rompe com a tradição clássica ao instaurar a temática do efêmero em sua poesia, admitindo imagens contemporâneas (atelier, tuyaux, mâts de la cité), quase todas buscadas dentro da nova configuração social que irrompe à sua época. Dessa maneira, o poeta aborda, poeticamente, um espaço físico e imaginário até então negligenciado ou simplesmente ignorado: $o$

2 Sobre alguns dos principais aspectos da disputa em torno do moderno, verificar, entre outros: KOCH, 1993; TOURAINE, 1994. 
centro urbano. Baudelaire trata do urbano ligando-o ao tema da efemeridade, o que confere, à sua poesia, um caráter absolutamente inovador.

O efêmero se configura, nos poemas baudelaireanos, principalmente através de vários paradoxos criados a partir da justaposição de temas antagônicos, principalmente a cidade e a natureza. O sujeito lírico se apresenta integrado a essa nova configuração espacial - e não como mero observador. Por essa razão, tem-se afirmado que, "para Baudelaire, a experiência estética fundia-se com a experiência histórica da modernidade [Modernität]" (HABERMAS, 1990).

Habermas (Idem) afirmou que, a partir de Baudelaire, a referência para a Modernidade passa a ser constituída de uma atualidade que se auto-consome. E já que essa atualidade não pode ser compreendida apenas como um período de transição, uma vez que se estabelece como centro da vida moderna, tampouco poderá ser buscada na oposição a épocas e figuras do passado. Assim sendo, "a atualidade só pode constituir-se como intersecção de tempo e eternidade" (Idem). Logo, tornase evidente que, ao propor a assimilação do eterno pelo efêmero, Baudelaire dá início a uma nova estética literária, diferente tanto da estética clássica quanto da estética modernista do século XVIII, de cunho predominantemente cientificista.

É na cidade grande que Baudelaire encontra o objeto poético ideal para construir a principal metáfora da Modernidade. A cidade representa, de forma sensível, as novas formas de organização social, decorrentes da crescente desintegração da ordem medieval, atuando como uma espécie de catalisador de todas as novas relações possíveis em um universo não mais organizado pela ordem clerical.

Do ponto de vista subjetivo, a atitude epistemológica frente a esse novo objeto é a flânerie, concebida como um ato eminentemente imaginário, visto que impõe, à observação dos objetos, um distanciamento solitário. A flânerie pode ser mais bem compreendida se oposta ao simples passeio, seguindo uma sugestão de Ferrara (1997, p. 196). No passeio, as imagens se apresentam estáticas, seguras e publicamente codificadas, garantindo a referencialidade da própria identidade urbana, através de alguns marcos, como a Torre Eifel, por exemplo. A flânerie, por sua vez, não decorre da mera observação, e sim, da reflexão, em que as imagens se colocam como "um pano de fundo, um recorte que sustenta uma caudal de sentimentos e reflexões” (Idem). Segundo a autora:

Se a imagem urbana era, sobretudo, visual e icônica, o imaginário é polissensorial e resgata índices, marcas, signos para, com esses fragmentos, produzir uma constelação, uma unidade que atua como metáfora da cidade: a solidão que se concretiza na multidão, o flâneur, a prostituta, o burguês, a velocidade são metáforas da modernidade e temas constantes do imaginário urbano (Idem, p. 198).

Em suma, Baudelaire não apenas representa a cidade grande como o espaço simultaneamente físico e imaginário em que se refletem os mais significativos mo- 
vimentos decorrentes da nova estruturação social em seu tempo, como também se apodera desse mesmo lugar, através da flânerie, para transformá-lo em uma metáfora da própria Modernidade. A seguir, esse processo será apresentado através de alguns exemplos retirados dos Quadros parisienses, sendo que será realizada uma análise aprofundada do poema Paysage.

\section{Paris TRansfigurada}

Segundo Walter Benjamin (1997, p. 161), nem a cidade grande tampouco a multidão constituem a verdadeira melodia de As flores do mal, apesar de ambas despontarem como os temas decisivamente novos na poesia baudelairiana. Benjamin afirma que "os verdadeiros objetos de As flores do mal se encontram em lugares mais invisíveis. São [...] as cordas jamais tocadas do instrumento inaudível em que Baudelaire devaneia" (Idem). Nessas cordas, soam, segundo o autor, seus três temas recorrentes, o satanismo, o spleen e o erotismo desviante.

Benjamin retrata, através desse paradoxo, a atitude perceptiva de Baudelaire, que se ancora na imaginação. É essa atitude que permite, ao poeta, realizar a transfiguração dos objetos urbanos de Paris em objetos imaginários capazes de representar o tema do moderno. O satanismo baudelairiano se manifesta juntamente com o seu culto ao presente eternamente efêmero; o spleen ou melancolia se expressa como uma tristeza profunda, vinculada ao sentimento de que o passado está se perdendo no presente e de que o presente não permanece; o erotismo desviante, por sua vez, procura e encontra amor e beleza no feio e no abjeto.

Alguns autores enxergam uma forte influência romântica quanto à temática da poesia baudelairiana, visto que o Romantismo já havia explorado temas como a solidão, a natureza idealizada e o misticismo demoníaco, por exemplo. Além disso, também tem sido afirmado que, na própria forma poética, Baudelaire leva adiante a tradição romântica, pois "na França, o romantismo, apesar do que se vangloriava Hugo, não depusera, ou pelo menos não desalojara, o alexandrino clássico [...]" (HYDE, 1989, p. 278).

Contudo, é necessário esclarecer que, diferente de grande parte dos românticos, Baudelaire não aborda tais temas apenas como expressão do pitoresco, do fantástico ou do sentimento da época. Em Baudelaire, os temas da solidão, do erotismo e do satanismo são transfigurados por uma espécie de alquimia, realizada a partir de um domínio exemplar da forma lírica tradicional, de um lado, e da utilização copiosa de antíteses e paradoxos, de outro. O resultado é que o efeito de subjetividade, na poesia baudelariana, torna-se desesperado, não conduzindo a uma superação mística apaziguadora, típica de autores como Coleridge, Keats, entre outros românticos. Em suma, Baudelaire realiza uma alquimia linguageira, através da qual emerge um espaço inatingível para a razão referencial - visto que se compõe de 
paradoxos - ou, nas palavras de Benjamin, surge uma metafisica do provocador (BENJAMIN, 1997, p. 11).

Os quadros parisienses parecem constituir o conjunto poético em que Paris representa, de forma exemplar, este novo espaço transfigurado. Neles, o satanismo e o erotismo despontam através da dispersão do eu lírico no espaço urbano, simultaneamente representado como espaço natural e como espaço místico. O resultado é um sentimento de profunda tristeza ou melancolia, caracterizado com o termo spleen, visto que as contradições ali apresentadas não encontram resolução. No poema Le cigne, por exemplo, Baudelaire retrata as muitas reformas arquitetônicas ocorridas na Paris do Segundo Império. Segundo Hyde (1989, p. 277), naquela época, proliferavam fachadas neoclássicas monumentais, e a cidade era

pela primeira vez servida por ruas planejadas [...] com esgotos e encanamentos de água absolutamente separados e distintos uns dos outros. Dava (ou pretendia dar) a impressão de um ressurgimento das glórias de Roma antiga; o primado das vias encarnava a idéia dominante de comunicações integrando o todo (Idem).

Baudelaire, por sua vez, inverte o significado desse projeto ufanista de reformas apelando para imagens do passado clássico ocidental, como a personagem Andrômaca, o rio Simeonte e o poeta Ovídio. Estes passam a ofuscar as imagens do presente - que pretende imitar o passado -, sugerindo que as reformas não passam de meras fachadas. O cisne, animal belo e garboso, é a metáfora utilizada para retratar tal inversão. Baudelaire o caracteriza como portador de gestes fous (gestos tresloucados) e o compara com os exilados, que são ridículos e sublimes. Ao passo que o cisne é transformado de símbolo do belo em pária urbano ${ }^{3}$, as reformas urbanas são transformadas em símbolo de imobilidade: "Paris change! mais rien dans ma mélancolie/ N'a bougé! [...]". Surge, portanto, um dos incontáveis paradoxos baudelairianos, que, aqui, transfigura o tema da mudança em imobilidade.

Ao passo que a beleza do cisne é transformada em símbolo de decadência, as imagens decadentes de Paris, por outro lado, transformam-se em objetos de apreciação estética. Por exemplo, em outro poema, Baudelaire transforma uma mendiga ruiva - caracterizada como pobre, dona de tamancos grosseiros e de meias estragadas - em símbolo do belo: " $V$ a donc, sans autre ornement,/ Parfum, perles, diamant,/ Que ta maigre nudité,/ O ma beautée? A mesma inversão ocorre com os Sete velhos, descritos como criaturas provindas de algum tipo de inferno ("du même enfer venu"), mas capazes de incitar um sentimento místico e religioso, voltado para a eternidade: “[...] malgré tant de décrépitude/ Ces sept monstres hideux avaient l'air éternel?".

Todos os demais objetos escolhidos por Baudelaire sofrem o mesmo tipo de inversão, como as velhinhas, os cegos, e as prostitutas. A atitude poética é, portanto,

3 A imagem do cisne como um dos párias urbanos de Baudelaire é de Hyde (1989, p. 279). 
criativa e transformadora, mas não apaziguadora. A metáfora utilizada para caracterizar o próprio fazer poético como atitude transformadora é o sol. Assim como o sol é amoral ("Ce père nourricier, ennemi des chloroses,/ Éveille dans les champs les vers comme les roses;"), uma vez que ilumina indistintamente tanto o verme como a rosa, o poeta também o é, pois exerce sua "estranha esgrima" tanto na cidade como no campo, tanto sobre os tetos quanto sobre os trigais ("Sur la ville et les champs, sur les toits e les blés"). Assim sendo, Baudelaire funde a imagem do sol com a do poeta, caracterizando a ambos como sujeitos capazes de vitalizar objetos imóveis. Ambos possuem o poder de redimir até mesmo as coisas mais abjetas por meio da luz e da vontade, criando os espaços complexos da vida e da poesia.

A análise pormenorizada do poema paysage, a seguir, pretende revelar alguns aspectos dessa configuração heterodoxa, composta pela urbanidade, pela natureza e pelo misticismo. Nos quatro primeiros versos, o eu lírico afirma que quer, para compor castamente suas éclogas, deitar-se junto ao céu, como os astrólogos, e escutar, sonhando, junto aos clochers (campanários), os seus hinos solenes levados pelo vento. A religiosidade ou misticismo está latente no advérbio castamente, ligado ao campanário (torre de uma igreja, em que ficam os sinos). Ela também está subjacente nos lexemas astrólogos e binos solenes. O pronome leurs, em frente a bymnes solennels, cria ambigüidade quanto ao possuidor: os hinos podem proceder dos sinos no campanário, ou dos astrólogos. Contudo, a despeito dessa ambivalência, a idéia do misticismo é mantida.

A figuração urbana externa aparece somente a partir do quinto verso, em que o sujeito lírico exclama que verá, com as duas mãos no queixo, do alto de sua mansarde, o "atelier qui chante e qui bavarde, les tuyaux, les clochers, ces mâts de la cite". Os lexemas mansarde, atelier, tuyaux e mâts apelam para uma descrição visual da paisagem urbana, vista do alto. No entanto, o lexema clochers, agora inserido entre elementos profanos, adquire uma ambivalência semântica, pois é, simultaneamente, um lugar religioso e não-religioso.

Além disso, essa ambivalência também está presente na fusão realizada entre mansarde e clocher. O único elemento semântico que mantém sua unidade é o aspecto da altura: tanto o campanário quanto a mansarda são lugares altos. No entanto, ao passo que a mansarda remete ao tempo presente, o campanário remonta ao passado eclesiástico. Logo, a ambivalência religiosa é paralela à ambivalência temporal.

Tanto o misticismo quanto a visualização da cidade são fundidos com o tema da natureza, completando um espaço semântico que poderia ser definido como espaço elevado, mistico-profano, passado-presente, urbano-natural. A natureza, apesar de oposta ao universo urbano, permanece como principal fonte temática da composição. $\mathrm{O}$ primeiro lexema que o comprova é écoglas (poemas pastoris), através do qual o eu lírico afirma, de início, que representará a cidade por uma forma poética bucólica. 
Além disso, há outros lexemas que apontam para a natureza como configuradora da urbanidade, tais como o céu, o vento, as brumas, a estrela, a lua e as estações do ano.

No verso 14, o eu lírico anuncia a chegada do inverno com suas neves monótonas, que o fará mudar de atitude frente à cidade: "Je fermerai partout portières e volets/ Pour bâtir dans la nuit mes féeriques palais". A observação da cidade, a partir do alto da mansarda/campanário, não é possível durante o inverno por causa do frio e da neve. Por isso, o eu lírico avisa que se recolherá para construir seus feéricos palácios. Deve-se notar que essa mudança de estado é apenas aparente, pois, no poema, não há diferença entre observar externamente e observar internamente, uma vez que, tanto do alto do campanário/mansarda quanto de dentro das portas e venezianas fechadas, o eu lírico transfigura a realidade que observa.

Nos versos 17 a 20, o sujeito lírico explicita o objetivo de sua imaginação, a saber, sonhar com horizontes azulados ("je rêverai des horizons bleuâtres"), com jardins, com jatos de água chorando em alabastros ("Des jardins, des jets d'eau pleurant dans les albâtres”), com beijos, pássaros cantando à tarde e à noite, e com tudo mais que o Idílio tenha de mais infantil (tout ce que l'Idylle a de plus enfantin). Nesses versos, de influência aparentemente romântica, predomina, novamente, a idéia de uma cidade lida como se fosse natureza. A paisagem externa será transformada, pelo sonho, em paisagem natural. $\mathrm{O}$ valor positivo da urbanidade será adquirido através de sua naturalização. Esse percurso temático é comprovado pelo verso 21, em que o mundo externo - representado pela multidão (L'Émeute) - tenta, em vão, desviar o poeta de sua voluptuosidade onírica ("L'Émente ... Na fera pas lever mon front de mon pupitre').

Os últimos quatro versos são elucidativos quanto à fonte de manipulação do sujeito lírico. Este afirma que será arrebatado por essa voluptuosidade de invocar, com sua vontade, a primavera, de tirar um sol de seu coração e de transformar seus pensamentos abrasantes em uma atmosfera tépida. O querer do eu lírico é investido de poder por meio do sonho. Portanto, o percurso temático que investe a cidade com o sema "natureza" completa seu caminho, visto que o sujeito quer e pode realizar a transformação da cidade não-natural em cidade natural. Assim, a Paris externa e urbana, que se apresenta, ao poeta, sob a metáfora da multidão, convertese em uma Paris idílica, inocente, infantil e, mesmo, bucólica, através de um simples ato de vontade, possibilitado pelo sonho ${ }^{4}$.

4 Essa tendência naturalista ou naturalizante é constante em toda a obra de Baudelaire, conforme atesta, entre outros, Hamburger: "Apesar de seu elogio ao culto do artifício, a imaginação de Baudelaire tendia a buscar na natureza os símbolos do "ideal”, e, nos fenômenos da civilização moderna, os símbolos da condição decadente, depravada e neurótica, que ele nomeou de "spleen" (HAMBURGER, 1991, p. 273). 
Pode-se concluir que a disposição paradoxal do tratamento conferido à temática da cidade, na poesia baudelairiana, desponta como um elemento estilisticamente inusitado em relação à tradição poética anterior. $O$ paradoxo constitui-se, de um lado, no fato de que a cidade situa-se em seu próprio tempo presente e, de outro, também em um espaço poético, marcado por repertórios derivados de tradições pretéritas. $O$ antagonismo decorre das contradições lógicas entre os dois mundos, ao passo que a harmonia é garantida pela coerência da construção poética, ancorada na própria tradição (métrica e melodia) e no desejo criador do poeta. Esse mesmo paradoxo se reflete na vontade de transformar o urbano em natural. Presente e passado, cidade e natureza, portanto, convivem de forma antagônica e harmônica.

Segundo Lucrécia Ferrara (1997, p. 197), em Baudelaire, é a modalidade de estímulo calcada no imaginário que dá origem a uma poética urbana identificada com a Modernidade. E Baudelaire, efetivamente, recria o imaginário parisiense, na medida em que apresenta a cidade sob a forma de um espaço em que convivem o passado e o presente, a religião e a não-religião, a natureza e a anti-natureza, numa transfiguração que leva o receptor para além da própria Paris, porém, sem jamais abandoná-la. Em suma, Baudelaire explora, pela primeira vez na história da literatura, um imaginário fundado na transitoriedade do presente, ligado à eternidade do passado, tomando a cidade como principal objeto poético. O resultado é o paradoxo, manifesto principalmente pelos sentimentos melancólicos do spleen, o apelo erótico em relação a objetos aparentemente repulsivos, além de um satanismo desesperado, ressoando, dessa forma, as cordas jamais tocadas do instrumento inaudivel em que Baudelaire devaneia, como sugere Benjamin. Tal é a Modernidade conforme concebida pela poesia de Charles Baudelaire. 


\section{REFERÊNCIAS}

BAUDELAIRE, Charles. As flores do mal. Rio de Janeiro: Nova Fronteira, 1985.

BENJAMIN, Walter. Charles Baudelaire: um lírico no ange do capitalismo. 3. ed. São Paulo: Brasiliense, 1997.

COMPAGNON, Antoine. Os cinco paradoxos da modernidade. Belo Horizonte: Ed. UFMG, 1996.

HABERMAS, Jürgen. O discurso filosófico da modernidade. Lisboa: Dom Quixote, 1990.

HAMBURGER, Michael. La verdad de la poesia: tensiones en la poesía moderna de Baudelaire a los años sesenta. Mexico: Fondo de Cultura Económica, 1991.

HYDE, G. M. A poesia da cidade. In: BRADBURY Malcolm; McFARLANE, James. Modernismo: guia geral, 1890-1930. São Paulo: Cia. das Letras, 1989.

FERRARA, Lucrécia d'Alessio. Cidade, imagem e imaginário. In: SOUZA, Célia Ferraz de; PESAVENTO, Sandra Jatahy. (Org.). Imagens urbanas: os diversos olhares na formação do imaginário urbano. Porto Alegre: Ed. UFRGS, 1997.

KOCH, Walter. The Roots of Literature. Bochum: Brockmeyer, 1993.

TOURAINE, Alain. Crítica da modernidade. Petrópolis: Vozes, 1994. 
